\title{
ЕЛЕКТРОНІКА
}

РАДІОТЕХНІКА

ЗАСОБИ ТЕЛЕКОМУНІКАЦІЙ

\author{
ELECTRONICS \\ RADIO ENGINEERING \\ TELECOMMUNICATION FACILITIES
}

I.Yu. Dmitrieva, Ph. D. phys.-math., Assoc. Prof., Odessa National Academy of Telecommunications named after O.S. Popov

\section{ANALYTICAL STUDY OF ELECTROMAGNETIC WAVE PROPAGATION IN THE FINITE HOMOGENEOUS LINES}

Introduction. It is well known that a lot of industrial and / or engineering problems in technical electrodynamics can be described analytically by the systems of PDEs (partial differential equations). Such mathematical modeling naturally implies corresponding solution, either numerical, or exact. In spite of development of computer techniques and variety of the standard subroutines, requirement of explicit investigation in modern electromagnetic theory remains urgent as well [1]. Here, those methods are mostly important that propose more or less general study algorithms. Thus, the first and the main stage in the effective analytic research of the finite-dimensional system of PDEs simulating various physical and engineering processes, is its matrix diagonalization procedure. It means that the original vector field problem is reduced to the equivalent totality of scalar equations where each of them depends on the only one unknown component of the initial vector field function. It is obvious, that further computation and mathematical simulation of the specific applied phenomena are simpler in scalar terms. The same fact can be affirmed for technical electrodynamics too.

Literature review. Basing on the aforesaid information, one can refer to [2] where the general diagonalization procedure is suggested for arbitrary finite-dimensional system of PDEs. The given approach represents operator analogy of the classical algebraic Gauss method, and corresponding theorem of applicability is proved there in [2]. Directly, those mentioned results are used in the case of arbitrary expofunctionally excited isotropic homogeneous medium mathematically determined by the specific differential Maxwell system that appeared at first in [3]. Though this system was investigated in the general classical spatial temporal form of $(x, y, z, t)$, its particular version of $(x, t)$ turns out to be rather interesting for practical industrial use. Application deals with the electromagnetic wave propagation under expofunctional influences in the various isotropic homogeneous lines with the different time intervals. So, the present studied system looks like 


$$
\left\{\begin{array}{l}
\partial_{1} H=\left(\sigma+\varepsilon_{a} \partial_{0}^{*}\right) E+j^{O S} \\
-\partial_{1} E=\left(r+\mu_{a} \partial_{0}^{*}\right) H+e^{O S},
\end{array}\right.
$$

where

$E, H=E, H(x, t)$ - are the unknown electric and magnetic field intensities;

$\sigma, \mu_{a}, \varepsilon_{a}=$ const $>0$ - are the specific conductivity, absolute magnetic and electric permeability of the medium;

$j^{O S}, e^{O S}=j^{O S}, e^{O S}(x, t)$ - are the given functions describing the outside current sources and intensities;

$\partial_{1}=\frac{\partial}{\partial x}, \partial_{0}^{*}=\partial_{0} \pm \lambda, \partial_{0}=\frac{\partial}{\partial t}$ - are the partial differential operators;

$\lambda=$ const $>0-$ is the signal parameter exciting the medium. Absorption of signal by the medium corresponds to "+", and activity of the medium implies "-";

$r=$ const $>0-$ is responsible for the system "symmetry" and simplifies mathematical calculations. At the end, it can be deleted without influence on either computing procedure, or on the original problem statement. $E, H, j^{O S}, e^{O S}$ belong to one and the same class of twice continuously differentiated functions over the space $(x, t)$, and structure of (1) determines order of derivative. Later, this functional class can be modified taking into account the particular boundary problem conditions. As it is shown in [4], system (1) can be reduced to the general wave PDE with respect to all unknown electromagnetic field intensities

$$
\left(\tilde{\partial}_{0}^{2}+\partial_{1}^{2}\right) F=\tilde{f}
$$

where

$$
\begin{aligned}
& F_{1}=E, F_{2}=H ; f_{1}=j^{o s}, f_{2}=e^{O S} ; F=\left[\begin{array}{l}
F_{1} \\
F_{2}
\end{array}\right], f=\left[\begin{array}{l}
f_{1} \\
f_{2}
\end{array}\right] ; \\
& \tilde{\partial}_{0}^{2}=\left(\sigma+\varepsilon_{a} \partial_{0}^{*}\right)\left(r+\mu_{a} \partial_{0}^{*}\right)=\varepsilon_{a} \mu_{a}\left(\partial_{0}^{*}\right)^{2}+\left(\sigma \mu_{a}+r \varepsilon_{a}\right) \partial_{0}^{*}+\sigma r-\text { is the differential polynomial op- }
\end{aligned}
$$
erator;

$$
\tilde{f}=\left[\begin{array}{c}
\tilde{f}_{1} \\
\tilde{f}_{2}
\end{array}\right]=\left[\begin{array}{c}
-\left(r+\mu_{a} \partial_{0}^{*}\right) f_{1}-\partial_{1} f_{2} \\
\partial_{1} f_{1}-\left(\sigma+\varepsilon_{a} \partial_{0}^{*}\right) f_{2}
\end{array}\right] \text { are the known functions. }
$$

Operator "power" is understood in its usual meaning as the consecutive operator application. Solvability criterion is proved also in [4] and it sounds like that: the specific case of the symmetrical differential Maxwell system (1) is solved explicitly in the meaning of its equivalence to the general scalar wave PDE (2) iff conditions

$$
\partial_{1}^{2}>\left(\frac{1}{2}\left(\sigma \sqrt{\mu_{a} / \varepsilon_{a}}-r \sqrt{\varepsilon_{a} / \mu_{a}}\right)\right)^{2}
$$

or

$$
\partial_{1}^{2} \leq\left(\frac{1}{2}\left(\sigma \sqrt{\mu_{a} / \varepsilon_{a}}-r \sqrt{\varepsilon_{a} / \mu_{a}}\right)\right)^{2}
$$

and

$$
\partial_{0} \neq \mp \lambda-\frac{\left(\sigma / \varepsilon_{a}+r / \mu_{a}\right) \pm \sqrt{\left(\sigma / \varepsilon_{a}-r / \mu_{a}\right)^{2}-4 \partial_{1}^{2} /\left(\mu_{a} \varepsilon_{a}\right)}}{2}
$$

are valid, and only non generalized functions are taken into account. 
The sign alteration in front of $\lambda$ is independent of the sign value near the square root. The given inequalities are understood in the meaning of their influence upon the respective considered functions.

Using the mentioned proven theorem, three types of boundary problems regarding (2) were proposed in [4...6] covering different lengths of lines and time intervals. Namely, [4] dealt with infinite lines and temporal arguments, [5] concerned both finite values of $x$ and $t$, [6] was connected with infinite lines and finite time intervals. It is strange, but the last possible version of finite $x$ and infinite $t$ remained out of consideration even till now.

Aim of the Research. So, the aim of the research is mathematical modeling and analytical study of electromagnetic wave propagation in the finite isotropic homogeneous lines under expofunctional excitations and arbitrary large time intervals.

Main Body. Respective boundary problem statement is written below

$$
\begin{cases}\left(\tilde{\partial}_{0}^{2}+\partial_{1}^{2}\right) F=\tilde{f}, x \in[0, l], t \in[0,+\infty) & \\ F(x, 0)=g_{1}(x), g_{1}(x)=\left[g_{11}(x), g_{12}(x)\right]^{T} ; & 0 \\ \left.F(x, t)\right|_{t \rightarrow+\infty}=0 ; & t \in[0,+\infty) \\ F(0, t)=g_{2}(t) ; & \\ F(l, t)=g_{3}(t), g_{j}(t)=\left[g_{j 1}(t), g_{j 2}(t)\right]^{T}(j=2,3),\end{cases}
$$

where $g_{1}(x), g_{j}(t)(j=2,3)$ - are the known continuous vector functions in the appropriate intervals;

$[,]^{T}$ means the transposed two-dimensional matrix column.

Results. An explicit solution of (3) is done by means of the Fourier finite integral sine transform application to the spatial variable $x[5]$ and considering temporal argument $t$ as the main one. Hence, integrating by parts twice $\frac{\pi}{l} \int_{0}^{l} \partial_{1}^{2} F(x, t) \sin \left(n \frac{\pi}{l} x\right) \mathrm{d} x=n\left(\frac{\pi}{l}\right)^{2}\left(-n \frac{\pi}{l} F_{n}(t)+(-1)^{n+1} g_{3}(t)+g_{2}(t)\right)$ and using this last expression, (3) is reduced to the boundary problem with respect to the Fourier integral sine transforms

$$
\left\{\begin{array}{l}
\left(\frac{d^{2}}{d t^{2}}+p \frac{d}{d t}+q\right) F_{n}(t)=f_{n}^{*}(t), t \in[0,+\infty) \\
F_{n}(0)={ }_{n} g_{1} ;\left.\quad F_{n}(t)\right|_{t \rightarrow+\infty}=0
\end{array}\right.
$$

where

$$
p=\sigma / \varepsilon_{a}+r / \mu_{a} \pm 2 \lambda, q=\lambda^{2} \pm \lambda\left(\sigma / \varepsilon_{a}+r / \mu_{a}\right)+\left(\sigma r-\left(\frac{\pi}{l}\right)^{3} n^{2}\right) /\left(\mu_{a} \varepsilon_{a}\right) \text { - are the constant co- }
$$

efficients;

$$
\begin{aligned}
& { }_{n} g_{1}=\frac{\pi}{l} \int_{0}^{l} g_{1}(x) \sin \left(n \frac{\pi}{l} x\right) d x \\
& F_{n}=F_{n}(t)=\frac{\pi}{l} \int_{0}^{l} F(x, t) \sin \left(n \frac{\pi}{l} x\right) d x ; \\
& \tilde{f}_{n}(t)=\frac{\pi}{l} \int_{0}^{l} \tilde{f}(x, t) \sin \left(n \frac{\pi}{l} x\right) d x ; \\
& f_{n}^{*}=f_{n}^{*}(t)=\left(\tilde{f}_{n}(t)+\left(\frac{\pi}{l}\right)^{2} n\left((-1)^{n} g_{3}(t)-g_{2}(t)\right)\right) /\left(\mu_{a} \varepsilon_{a}\right) \text { - are the corresponding Fourier sine }
\end{aligned}
$$

finite transforms whose right or left lower indices $n$ mean transformation operation. 
Solving linear ODE (ordinary differential equation) from (4) by means of the same classical apparatus as in [4...6], one gets the unknown transform of electromagnetic field intensities

$$
F_{n}=\sum_{j=1}^{2} \exp \left(\omega_{j} t\right)\left(C_{j}+\left((-1)^{j+1} s_{j}(t)\right) / \sqrt{D}\right), \forall C_{j}=\text { const } \in R,
$$

where

$s_{j}(t)=\int \exp \left(-\omega_{j} t\right) f_{n}^{*}(t) d t(j=1,2)-$ are the given functions;

$\sqrt{D}=\omega_{1}-\omega_{2}, \omega_{j}=\frac{-p+(-1)^{j+1} \sqrt{D}}{2}(j=1,2), \quad D=\left(\frac{\sigma}{\varepsilon_{a}}-\frac{r}{\mu_{a}}\right)^{2}+4\left(\frac{\pi}{l}\right)^{3} \frac{n^{2}}{\mu_{a} \varepsilon_{a}}>0$ - are the found numerical values from the aforesaid ODE's solving process.

Further, after realization of both initial conditions from (4), the unknown arbitrary constants $C_{j}(j=1,2)$ should be sought from the following system

$$
\left\{\begin{array}{l}
C_{1}+C_{2}={ }_{n} g_{4} \\
C_{1} \exp \left(\omega_{1} t\right)+\left.C_{2} \exp \left(\omega_{2} t\right)\right|_{t \rightarrow+\infty}={ }_{n} g_{5} .
\end{array}\right.
$$

Taking into account physical character of $\tilde{f}_{n}(t)$ formed by $j_{n}^{O S}, e_{n}^{O S}$, it is natural to accept $\left.\tilde{f}_{n}(t)\right|_{t \rightarrow+\infty}=0$. Hence, ${ }_{n} g_{5}$ from (6) is the following

$$
{ }_{n} g_{5}=\left.\frac{1}{\sqrt{D}} \sum_{j=1}^{2}(-1)^{j} s_{j}(t) \exp \left(\omega_{j} t\right)\right|_{t \rightarrow+\infty},
$$

and

$$
\left.s_{j}(t)\right|_{t \rightarrow+\infty}=\left.\frac{1}{\mu_{a} \varepsilon_{a}} \int \exp \left(-\omega_{j} t\right)\left(\frac{\pi}{l}\right)^{2} n\left((-1)^{n} g_{3}(t)-g_{2}(t)\right) d t\right|_{t \rightarrow+\infty} .
$$

In (6), transform

$$
{ }_{n} g_{4}={ }_{n} g_{1}+\frac{1}{\sqrt{D}} \sum_{j=1}^{2}(-1)^{j} s_{j}(0)
$$

does not depend on $t$ and represents const while $t \rightarrow+\infty$.

Relying on (7)...(9), those required $C_{j}(j=1,2)$ from (6) can be written uniformly

$$
C_{j}=\left.\frac{(-1)^{j+1}}{1-\exp (-t \sqrt{D})}\left(\frac{1}{\sqrt{D}}\left(s_{2}(t) \exp (-t \sqrt{D})-s_{1}(t)\right)-{ }_{n} g_{4} \exp ((j-2) t \sqrt{D})\right)\right|_{t \rightarrow+\infty}(j=1,2) .
$$

Since $\lim _{t \rightarrow+\infty} \exp (-t \sqrt{D})=0$, it is obvious to assume the mildest sufficient condition for $s_{2}(t)$ in (10), as being bounded at infinity. The latter requirement jointly with convergence of $s_{1}(t)$ at the infinite point

$$
\exists \lim _{t \rightarrow+\infty} s_{1}(t)=\text { const }_{1} \neq \infty
$$

takes (10) to the following expression

$$
C_{j}=(-1)^{j+1}\left((1-j)_{n} g_{4}-\frac{\text { const }_{1}}{\sqrt{D}}\right)(j=1,2) .
$$

Substitution of (12) for (5) gives required solution of the transformed problem (4)

$$
F_{n}=\frac{1}{\sqrt{D}} \sum_{j=1}^{2}(-1)^{j+1} \exp \left(\omega_{j} t\right)\left((1-j)_{n} g_{4} \sqrt{D}-\text { const }_{1}+s_{j}(t)\right) .
$$


Verification of (13) satisfying to the first initial condition and ODE from (4) is trivial. Checking of the second initial condition from (4) in terms of (13) is not so simple and is reduced to the following expression by application of (11)

$$
\left.F_{n}(t)\right|_{t \rightarrow+\infty}=\left.\frac{1}{\sqrt{D}} \exp \left(\omega_{2} t\right)\left(_{n} g_{4} \sqrt{D}+\text { const }_{1}-s_{2}(t)\right)\right|_{t \rightarrow+\infty} .
$$

Taking into account (9), (11) and boundedness of $\left.s_{2}(t)\right|_{t \rightarrow+\infty}$, the whole sum inside of the round brackets from (14) appears bounded while $t \rightarrow+\infty$. Further, turning back to $\omega_{2}$ that is written above after (5), one can notice that $\omega_{2}<0$ for arbitrary positive " $+\lambda$ " in $p$, when absorption of signal takes place. Hence, the right part of (14) equals zero, and the second initial condition from (4) is true. Nevertheless, even for " $-\lambda$ " in $p$, when activity of the medium exists, $p$ can be made positive in the case of any $\lambda>0$ numerical value. It is absolutely natural because of the structure of $p$ represented by formula after (4) and original meaning of $r$ as an extra theoretical positive constant (look explanations of (1)). So, for each possible value of $\lambda>0$ in the presence of activity of the medium while " $-\lambda$ " in (1), (3), (4), $r>0$ can be accepted as big, as it is claimed by inequality $p=\sigma / \varepsilon_{a}+r / \mu_{a}-2 \lambda>0$. Therefore, even in this case $\omega_{2}<0$, and the right part of (14) is zero. As the result, the second initial condition from (4) is checked and confirmed completely.

Application of the inverse Fourier sine finite transform $\frac{2 l}{\pi^{2}} \sum_{n=1}^{\infty} \sin \left(n \frac{\pi}{l} x\right)$ to (13) forms the wanted explicit solution of the original boundary problem (3), i.e. function

$$
\begin{gathered}
F(x, t)=\frac{2 l}{\pi^{2}} \sum_{n=1}^{\infty} F_{n}(t) \sin \left(n \frac{\pi}{l} x\right)= \\
=\frac{2 l}{\pi^{2} \sqrt{D}} \sum_{n=1}^{\infty} \sum_{j=1}^{2}(-1)^{j+1} \exp \left(\omega_{j} t\right)\left((1-j)_{n} g_{4} \sqrt{D}-\text { const }_{1}+s_{j}(t)\right) \sin \left(n \frac{\pi}{l} x\right)
\end{gathered}
$$

that describes the electromagnetic field behavior. The last result means that the goal of the present paper is completely attained.

Conclusions. Though the shortcoming of given article is the lack of particular numerical computations, it can be covered by virtue of (15). Really, all possible engineering phenomena analytically determined by (1), (3) have general explicit solution (15) that simplifies even computer calculus. Required electromagnetic field intensities for various types of lines and different time intervals are got by direct substitution of $\sigma, \mu_{a}, \varepsilon_{a}, l$, etc. for (15) without any approximate calculating procedure.

Moreover, the proven criterion reduces original vector field statement to the equivalent general scalar wave PDE that incomparably easier to solve. Construction of corresponding boundary problems based on this equation and mathematically simulating investigated engineering or physical process is also more obvious than dealing with initial matrix formulation.

Suggested approach can be applied effectively to arbitrary finite-dimensional systems of PDEs analytically describing physical and industrial phenomena. Present results can be used for mathematical modeling and analytical study of the relevant modern problems in radio engineering and telecommunications.

\section{Literature}

1. Proceedings of the International Scientific Conference on the Mathematical Methods in Electromagnetic Theory (MMET 12), Kharkov, August 2012. — Danvers: IEEE, 2012. — 594 p.

2. Dmitrieva, I.Yu. Diagonalization of the differential operator matrix in the case of the multidimensional circuits / I.Yu. Dmitrieva, A.M. Ivanitckiy // Наукові праці ОНАЗ ім. О.С. Попова. — 2009. — № 1. — C. $36-51$. 
3. Иваницкий, А.М. Зависимость третьего и четвертого уравнений Максвелла от первых двух при произвольном возбуждении электромагнитного поля / А.М. Иваницкий // Наукові праці ОНАЗ ім. О.С. Попова. - 2004. - № 2. - C. $3-7$.

4. Dmitrieva, I.Yu. Signal propagation in semi-infinite lines and its mathematical representation / I.Yu. Dmitrieva // Пр. Одес. політехн. ун-ту. — Одеса, 2013 - Вип. 2(41). - С. 261 - 266.

5. Dmitrieva, I. Mathematical modeling of wave propagation in the finite homogeneous lines / I. Dmitrieva // Hyperion International Journal of Econophysics \& New Economy. — 2013. — Vol. 6, Iss. 2. - PP. $219-229$.

6. Дмитрієва, I.Ю. Поширення електромагнітних хвиль в однорідних лініях при експофункціональних впливах / І.Ю. Дмитрієва // Наукові праці ОНАЗ ім. О.С. Попова. - 2013. № $1 .-$ C. $77-82$.

\section{References}

1. Proceedings of the International Scientific Conference on the Mathematical Methods in Electromagnetic Theory (MMET 12), Kharkov, August 2012. — Danvers: IEEE, 2012. — 594 p.

2. Dmitrieva, I.Yu. Diagonalization of the differential operator matrix in the case of the multidimensional circuits / I.Yu. Dmitrieva, A.M. Ivanitskiy // Naukovi pratsi ONAZ im. O.S. Popova [Proceedings of ONUC]. - 2009. — \# 1. - pp. $36-51$.

3. Ivanitskiy, A.M. Zavisimost' tret'ego i chetvertogo uravneniy Maksvella ot pervykh dvukh pri proizvol'nom vozbuzhdenii elektromagnitnogo polya [Dependence of the third and fourth Maxwell equations upon the first two at arbitrary excitation of electromagnetic field] / A.M. Ivanitskiy // Naukovi pratsi ONAZ im. O.S. Popova [Proceedings of ONUC]. - 2004. - \# 2. - pp. $3-7$.

4. Dmitrieva, I.Yu. Signal propagation in semi-infinite lines and its mathematical representation / I.Yu. Dmitrieva // Pratsi Odeskoho politekhnichnoho universytetu [Proceedings of Odesa Polytechnic University]. — Odesa, 2013 - Iss. 2(41). — pp. 261 - 266.

5. Dmitrieva, I. Mathematical modeling of wave propagation in the finite homogeneous lines / I. Dmitrieva // Hyperion International Journal of Econophysics \& New Economy. - 2013. — Vol. 6, Iss. 2. - pp. $219-229$.

6. Dmytriieva, I.Yu. Poshyrennia elektromahnitnykh khvyl v odnoridnykh liniiakh pry ekspofunktsionalnykh vplyvakh [Electromagnetic wave propagation in the homogeneous linesunder expofunctional excitations] / I.Yu. Dmytriieva // Naukovi pratsi ONAZ im. O.S. Popova [Proceedings of ONUC]. 2013. - \# 1. - pp. $77-82$.

\section{АНОТАЦІЯ / АННОТАЦИЯ / ABSTRACT}

І.Ю. Дмитрісва. Аналітичне дослідження поширення електромагнітних хвиль у кінцевих однорідних лініяx. Запропоновані результати $\epsilon$ частковим випадком загального наукового напряму, пов'язаного $з$ математичним моделюванням та аналітичним вивченням явищ електромагнітного поля, що описуються системами ЧДР (диференціальних рівнянь у частинних похідних). Специфічний електродинамічний інженерний процес задано диференціальною системою Максвелла, ефективне дослідження якої припускає коректну теоретичну та фізичну постановку у термінах загального хвильового ЧДР відносно всіх функцій напруженості поля. Базуючись на цьому рівнянні, відповідна крайова задача визначає поширення електромагнітних хвиль в ізотропних однорідних кінцевих лініях при наявності експофункціональних збуджень та у скільки завгодно великих проміжках часу. Явне розв'язання зазначеної задачі знаходиться побудовою оберненого матричного оператора і методом інтегральних перетворень. Доведено також критерій розв'язання, що забезпечує коректність фізичних/інженерних умов і математичну техніку обчислень. Запропонований аналітичний підхід $\epsilon$ частиною загального методу щодо детального дослідження поведінки електромагнітного поля у різних середовищах.

Ключові слова: диференціальна система Максвела, загальне хвильове рівняння, крайова задача відносно напруженості електромагнітного поля.

И.Ю. Дмитриева. Аналитическое исследование распространения электромагнитных волн в конечных однородных линиях. Предложенные результаты представляют частный случай общего научного направления, связанного с математическим моделированием и аналитическим изучением явлений электромагнитного поля, описываемых системами ЧДУ (дифференциальных уравнений в частных производных). Специфический электродинамический инженерный процесс задается дифференциальной системой Максвелла, эффективное исследование которой подразумевает корректную теоретическую и физическую постановку в терминах общего волнового ЧДУ относительно всех напряженностей поля. Основываясь на этом уравнении, соответствующая краевая задача определяет распространение электромагнитных волн в изотропных однородных конечных линиях при экспофункциональных 
возбуждениях и сколь угодно больших промежутках времени. Явное решение упомянутой задачи находится посредством построения обратного матричного оператора и метода интегральных преобразований. Доказан также критерий разрешимости, обеспечивающий корректность физических/инженерных условий и математическую технику вычислений. Предложенный аналитический подход представляет часть общего метода, детально исследующего поведение электромагнитного поля в различных средах.

Ключевые слова: дифференциальная система Максвелла, общее волновое уравнение, краевая задача относительно напряженностей электромагнитного поля.

I.Yu. Dmitrieva. Analytical study of electromagnetic wave propagation in the finite homogeneous lines. The suggested results represent a special case of the general scientific trend dealing with mathematical modeling and analytical study of electromagnetic field phenomena described by the systems of PDEs (partial differential equations). A specific electrodynamic engineering process is specified by the differential Maxwell system whose effective research implies correct theoretical and physical statement in terms of the general wave PDE regarding all field intensities. Based on this equation, the corresponding boundary problem determines electromagnetic wave propagation in the isotropic homogeneous finite lines under expofunctional excitations and arbitrary large time intervals. Explicit solution of the aforesaid problem is found using inverse matrix operator construction and the integral transform method. Solvability criterion is also proved, supporting correctness of the physical/engineering conditions and mathematical computing technique. The proposed analytic approach represents part of the general method investigating electromagnetic field behavior for arbitrary media in detail.

Keywords: Maxwell differential system, general wave equation, boundary problem regarding electromagnetic field intensities.

Reviever Dr. techn. sciences, Prof. of Odesa nat. polytechnic univ. Maksimov M.V.

Received May 5, 2014

N.I. Kushnirenko, engineer, V.Ya. Chechelnytskyi, Dr. techn. sciences, Prof., Odes. Nat. Polytechn. Un-ty

\section{DIGITAL MODULATION METHOD BASED ON PERFECT BINARY ARRAYS}

Introduction. Modern telecommunication systems operating in a multipath propagation conditions must possess high resilience, robustness and secrecy. It is known [1] that the secrecy primarily determined by the energetic and parametric secrecy. Noise-like signals are commonly used to ensure communication secrecy. Such signals are built on the basis of certain algebraic structures.

Term "noise-like signals" is referred to the signals, for which the product of their bandwidth $F$ and elementary symbol duration $T$ is much greater than 1 . This product is called the processing gain and denoted as $B$, i.e. 78

$$
B=F T .
$$

For the noise-like signals the processing gain $B<1$. The wider bandwidth $F$ of noise-like signal, which is the spreading code (1), the higher the energetic and parametric secrecy of communication. The frequency of noise-like signals changing and their selection from the signal ensemble depends on many requirements to a communication system and can't be unambiguously determined [1].

Literature review. Noise-like signals can be designed using various structures. More recently, the heightened attention in domestic and foreign papers is paid to the application of Perfect Binary

DOI: 10.15276/opu.1.43.2014.37

(C) N.I. Kushnirenko, V.Ya. Chechelnytskyi, 2014

ЕЛЕКТРОНІКА. РАДІОТЕХНІКА. ЗАСОБИ ТЕЛЕКОМУНІКАЦІЙ 